\section{AB0873 CHARACTERISTICS OF ADHERENCE, PERSISTENCE AND THERAPEUTIC ALLIANCE IN PATIENTS WITH GOUT}

E. Alvarez-Hernandez ${ }^{1}$, L.D. Upegui-Arango ${ }^{2}$, J. Vazquez-Mellado ${ }^{1}$, E. Aranda-Arreola ${ }^{1}$, R. Burgos-Vargas ${ }^{1}$, I. Pelaez-Ballestas ${ }^{1} .{ }^{1}$ Rheumatology, Hospital General de Mexico, Mexico DF, Mexico; ${ }^{2}$ Rheumatology, 2.Universidad Industrial de Santander, Bucaramanga, Colombia

Background: Adherence is the extent to which the patient takes their medications and follow the directions prescribed by their doctor. It has two components: compliance (the degree or extent of conformity to the recommendations about day-to-day treatment by the provider with respect to the timing, dosage, and frequency) and persistence (the duration of time from initiation to discontinuation of therapy). The therapeutic alliance is the patient physician relationship that allows the patient to participate actively in their treatment. The reported adherence varies from 43 to $78 \%$ in patients with chronic diseases. In gout, the adherence varies from 10 to $46 \%$.

Objectives: To evaluate the characteristics of adhesion in patients with gout.

Methods: Patients with gout from the GRESGO cohort were included. Sociodemographic, clinical, and treatment data were collected and the HAQ-DI, EuroQol-5d and a specific questionnaire of adherence and therapeutic alliance were applied.

Results: The study included 238 patients $(97.1 \%$ male), whit a mean age of $47.7 \pm 12.7$ years, educational level $9.2 \pm 4.2$ years. The adherence index (prescribed doses/doses taken) was $86 \%$. Only $28.6 \%$ never stopped treatment. $4.6 \%$ took the doses at the correct time. Most frequent causes of suspension were lack of supply $(37 \%)$ and forgetfulness $(30 \%)$. Only $5 \%$ buy all of their medications, $10 \%$ follow the lifestyle changes. $49.6 \%$ do not take the medication when they disagree with their doctor.

Conclusions: Despite having a good adherence index there are discrepancies with the qualitative answers, since more than $70 \%$ did not have good persistence and more than $90 \%$ did not comply with the schedule.

Disclosure of Interest: None declared

DOI: 10.1136/annrheumdis-2017-eular.6680

\section{AB0874 CHARACTERISTICS OF GOUT IN CAMEROON, CENTRAL AFRICA: A HOSPITAL-BASED STUDY}

M.S. Doualla, F. Kamdem, F. Kemta Lekpa. Service de Médecine Interne, Douala General Hospital, Douala, Cameroon

Background: Few data are available on the characteristics of gout in sub-Saharan Africa (1).

Objectives: We performed this study with the aim to present the clinical, laboratory and imaging characteristics of gout at the time of diagnosis in Cameroon.

The results obtained will be compared with data from the Western literature.

Methods: We performed a cross-sectional study among the 10,186 out patients seen at the Rheumatology unit of Douala General Hospital, Douala, Cameroon, between 2004 and 2014. We included patients with gout diagnosis (ACR criteria 1977). The main socio-demographic and clinical data on gout at the time of diagnosis were collected.

A $p<0.05$ was significant.

Results: We included 511 patients (5.02\%) including 415 men and 96 women. The mean age was $55.9 \pm 10.8$ years.

Joint pain $(n=508,99.4 \%)$, joint effusion $(n=198,38.7 \%)$ and fever $(n=20,3.9 \%)$ were the main reasons for consultation at diagnosis. Knees $(n=300,62.6)$, ankles $(n=187,39.0 \%)$ and MTP1 joints $(n=128,26.7 \%)$ were the most affected joints. Tophi were mainly located at the elbows $(n=72,66.0 \%)$, MTP1 $(n=20,18.3 \%)$, and ears $(n=18,16.5 \%)$ [Table 1]

Gout was as acute $(n=255,49.9 \%)$ as it was chronic $(n=256,50.1 \%)$. The clinical presentation was oligoarticular in 195 patients $(38.7 \%)$, monoarticular in 172 patients $(34.1 \%)$, and polyarticular in 137 patients $(27.2 \%)$.

The mean uric acid level was $82.4 \pm 22.3 \mathrm{mg} / \mathrm{L}$, with hyperuricemia found in 401 patients $(78.4 \%)$. Elevated acute phase reactants was present in $81.9 \%$ of patients. Structural involvements related to gout were present in $181(74.8 \%)$ of the 241 patients who had performed an X-ray.

Comorbidities were present in 344 patients $(67.3 \%)$, hypertension $(n=208,40.7 \%)$, obesity $(n=151,29.5 \%)$, osteoarthritis $(n=111,21.7 \%)$, oesogastroduodenal

Table 1. Localization of gouty arthritis and tophi

\begin{tabular}{lcllc}
\hline \multicolumn{2}{ll}{ Joint stiffness and/or tenderness } & & & \multicolumn{1}{l}{ Tophi location } \\
\cline { 1 - 2 } & $\mathrm{n}(\%)$ & & & $\mathrm{n}(\%)$ \\
\hline Knee & $300(62.6)$ & & Elbow & $72(66.0)$ \\
Ankle & $187(39.0)$ & & MTP1 & $20(18.3)$ \\
MTP1 & $128(26.7)$ & & Ear & $18(16.5)$ \\
Wrist & $93(19.4)$ & & Wrist & $10(9.2)$ \\
Elbow & $81(16.9)$ & & PIP & $9(8.2)$ \\
PIP & $56(11.7)$ & & Foot & $9(8.2)$ \\
MCP & $53(11.1)$ & & IDP & $8(7.3)$ \\
Foot & $50(10.4)$ & & Ankle & $8(7.3)$ \\
Shoulder & $49(10.2)$ & & Knee & $8(7.3)$ \\
Others MTP & $24(5.0)$ & & Others MTP & $6(5.5)$ \\
DIP & $15(3.1)$ & & MCP & $5(4.6)$ \\
Others & $30(6.3)$ & & Achille tendon & $1(0.9)$ \\
& & & Imprecises location & $18(16.5)$ \\
\hline
\end{tabular}

complaints $(n=74,14.5 \%)$, diabetes $(n=52,10.2 \%)$, and chronic kidney diseases $(\mathrm{n}=42.8 .2 \%)$

Associated factors $(p<0.05)$ in the occurrence of gout were obesity, alcohol intake, diuretics intake, and menopause (in women).

Conclusions: Gout has the same clinical, laboratory and imaging characteristics in Cameroon than in Western countries. The main difference comes from the place of the knee as the main joint involved by gouty arthritis at the time of diagnosis in our study.

References:

[1] Usenbo A, et al. PLoS One. 2015 Aug 4;10(8):e0133858.

Disclosure of Interest: None declared

DOI: 10.1136/annrheumdis-2017-eular.6990

\section{AB0875 DO WE CONTROL GOUT IN PRIMARY CARE FOLLOWING EULAR RECOMMENDATIONS?}

F. Leon Vazquez ${ }^{1}$, C. Sanz Rodrigo ${ }^{2}$, C. Muñoz Martínez de Salinas ${ }^{2}$, M. Ferruelo Magán ${ }^{2}$, M. Metola Gómez ${ }^{2}$, A. Del Caño Garrido ${ }^{1}$, C. González Fernández ${ }^{2} \cdot{ }^{1}$ CS San Juan de la Cruz, Servicio Madrileño de Salud, Pozuelo de Alarcón (Madrid); ${ }^{2}$ CS Puerta Bonita, Servicio Madrileño de Salud, Madrid, Spain

Background: Inadequate control of hyperuricaemia in gout patients can lead to more arthritis, activity limitations and higher gout-related treatment costs. General Practitioners can use well tolerated urate-lowering drugs, but some patients are inadequately controlled. European League against Rheumatism (EULAR) has published new guidelines ${ }^{1}$ in 2016 with similar serum Uric Acid (sUA) goals.

Objectives: To evaluate sUA control in patients diagnosed with gout who were attended in primary care and to compare them to EULAR 2016 guidelines ${ }^{1}$.

Methods: Retrospective analysis, carried out in 2 primary care health centres (8 family doctors) in Spain. We selected patients that have consulted in the last year diagnosed with gout at any time. Demographic variables, gout-related drugs and last sUA level were collected. Adequate control was defined as sUA level $<6$ $\mathrm{mg} / \mathrm{dL}$.

Limitations: We used only one isolated SUA value. No drug doses were analyzed. We did not distinguish severe from mild gout.

Ethical-legal aspects: We did not identify the patients. There was no intervention. Results: We analyzed 231 patients diagnosed with gout, mean 70.1 years-old (Confidence Interval $\mathrm{Cl}_{95 \%}$ 68.3-72.0), 189 (81.8\%) were men. The mean sUA was $6.55 \mathrm{mg} / \mathrm{dL}\left(\mathrm{Cl}_{95 \%} 6.31-6.79 \mathrm{mg} / \mathrm{dL}\right)$.

$39 \%$ were adequately controlled according to EULAR (sUA $<6 \mathrm{mg} / \mathrm{dL}$ ), $25.5 \%$ were close to the objective $(6-7 \mathrm{mg} / \mathrm{dL})$ and clearly inadequate $(>7 \mathrm{mg} / \mathrm{dL})$ in $35.5 \% .10 \%$ had really bad control (sUA $>9 \mathrm{mg} / \mathrm{dL}$ ).

There was no difference between control in male $6.58 \mathrm{mg} / \mathrm{dL}\left(\mathrm{IC}_{95 \%} 6.33-6.83\right)$ and female $6.40 \mathrm{mg} / \mathrm{dL}\left(\mathrm{Cl}_{95 \%}\right.$ 5.73-7.07). Control improves in elder people: $<60$ years $7.01 \mathrm{mg} / \mathrm{dL}\left(\mathrm{Cl}_{95 \%} 6.60-7.42\right)$ vs. $>70$ years $6.30 \mathrm{mg} / \mathrm{dL}\left(\mathrm{Cl}_{95 \%} 6.00-6.60\right)$ The only 14 patients receiving febuxostat achieved similar control using allopurinol (6.5 versus $6.7 \mathrm{mg} / \mathrm{dL}$ ).

Conclusions: The degree of control of sUA in primary care patients in our area is mostly between optimal and acceptable, but it can be optimized in more than half of the cases. In a few patients the control is lousy. The worst-controlled patients were the youngest.

References:

[1] Richette P, Doherty M, Pascual E, Barskova V, Becce F, Castañeda-Sanabria J, Coyfish M, Guillo S, Jansen TL, Janssens H, Lioté F, Mallen C, Nuki G, Perez-Ruiz F, Pimentao J, Punzi L, Pywell T, So A, Tausche AK, Uhlig T, Zavada J, Zhang W, Tubach F, Bardin T. 2016 updated EULAR evidencebased recommendations for the management of gout. Ann Rheum Dis. 2017 Jan;76(1):29-42. http://ard.bmj.com/content/76/1/29.abstract.

Disclosure of Interest: None declared

DOI: 10.1136/annrheumdis-2017-eular.6961

\section{AB0876 OSTEOMALACIA: MODALITIES OF PRESENTATION AND ETIOLOGY OF 20 CASES}

H. Mouanaa, Z. Saoussen, A. Arfa, M. Jguirim, I. Bejia, M. Touzi, N. Bergaoui. Rheumatology Unit of the Monastir University Hospital, Monastir, Tunisia

Background: Osteomalacia is a defect of mineralization of the protein framework of the skeleton.

Objectives: We try through our series to determine the presentation modalities and the various causes of this fragile benign osteopathy.

Methods: It is a descriptive retrospective study of cases collected in our rheumatology department between 2001 and 2016, concerning patients with osteomalacia

Results: Twenty patients were collected: 13 women and 7 men with an average age of $53 \pm 19$ years [22 years, 80 years]. The mean duration of the disease is 45 months [5-172]. The findings were: bone pain in $55 \%$ of cases, pelvic pain in $45 \%$ of cases, a waddling gait in 5 cases (25\%), fractures with low energy in $40 \%$ of cases, Functional impotence of the lower limbs in $35 \%$ of cases and a biological discovery in 2 cases $(10 \%)$. Hypocalcemia, phosphorus deficiency and hypocalciuria were found in 14 cases, ie $70 \%$. Alkaline phosphatases were elevated in 12 cases, with a variable rate of 2 to 7 times normal.The PTH, performed in 17 cases, was elevated in $53 \%$ of the cases. In our series, all 
patients had hypovitaminosis D. In addition, an associated iron deficiency anemia was detected in $50 \%$ of the cases, biological stigma of digestive malabsorption in $40 \%$ of the cases and renal insufficiency in $15 \%$ of the cases. Standard radiographs showed diffuse demineralization in $90 \%$ of cases, Looser-Milkman streaks in $40 \%$ of cases and fractures in $30 \%$ of cases. Bone scintigraphy among 8 patients revealed diffuse hyperfixation in 4 cases $(50 \%)$, localized hyperfixation in 3 cases $(37 \%)$ and non conclusive images in only one case $(12.5 \%)$. Bone densitometry performed in 5 patients showed secondary osteoporosis in $80 \%$ of cases. The diagnosis of osteomalacia was retained in 2 cases, celiac disease in 5 cases, renal insufficiency in 1 case, phosphate diabetes in 3 cases including Fanconi syndrome, hypophosphatasia in one case and tubular involvement as part of ankylosing spondylitis In one case. Etiology was a neoplastic cause in 4 cases including multiple myeloma. All the patients had a vitamin-calcium treatment (calcium intake between $500 \mathrm{mg}$ and $2 \mathrm{~g}$ per day with an average of $2.5 \mathrm{cp} / \mathrm{d}$, phosphorus in 3 cases and an etiological treatment in 3 cases. The resection of the tumor was the reason behind a clinical-biological improvement in the case of thyroid tumors. The outcome was favorable in the short term for all cases.

Conclusions: Osteomalacia is a generalized benign osteopathy, essentially linked to a deficiency in vitamin $D$ often unrecognized. The diagnosis is simple and the treatment is easy, but the ignorance of the etiological forms can be responsible for an unfavorable evolution.

Disclosure of Interest: None declared

DOI: 10.1136/annrheumdis-2017-eular.6986

\section{AB0877 APPLICATION OF GOUT DIARY IN HEALTH EDUCATION OF GOUT PATIENTS}

H. Miao, L. Zhang, G. Zhang, K. Xu. Rheumatology, Shanxi dayi hospital, Taiyuan, China

Background: Gout is a heterogeneous disease characterized by increased levels of blood uric acid. It is difficult to achieve a comprehensive and effective control of gout only by drugs, drug therapy must be combined with health education, diet and lifestyle changes. However, most of the gout patients had wrong thinking about their disease, diet and drug therapy. The status of China's health education in gout patients:the research teams were dispersed and unstable, the content of health education needed to be further refined, the models of health education were very simple.Based on the traditional models of health education,the purpose of this study is to explore the effect of gout diary in gout patients, by recording gout diary in order to improve their daily life behaviors and related laboratory indexes, aim to provide a new method for health education of gout patients.

Objectives: In order to explore the effect of gout diary,we applied the gout diary in gout patients.

Methods: From January 2015 to December 2015,110 cases of gout hospitalized patients were randomly divided into study group and control group $(n=55)$. The control group used traditional education models:patient education forum,gout handbook,patient group discussion,etc.Based on the control group,the research group used not only the traditional education models, but also added gout diary, the patient can record the diary by themselves. In order to evaluate the effect of gout diary,we used questionnaires and related laboratory indexes.

Results: The research group had significant improvement in laboratory indexes, healthy behaviors and life style $(P<0.05)$,such as quit smoking, quit drinking, according to the doctors' suggestions, pay more attention to their blood uric acid and other laboratory indexes, see the doctor regularly, maintain ideal body weight,exercise regularly,working and resting regularly,keeping happy mood. Conclusions: Apply the gout diary in gout patients, we can achieve a perfect effect.

References:

[1] Li Yun Zhang, MD, H. Ralph Schumacher, Hou Heng Su, et al.Development and Evaluation of a Survey of Gout Patients Concerning Their Knowledge About Gout. Journal of Clinical Rheumatology[J]. 2011, 8,17(5):1-7.

[2] Glazebrook KN, Guimaraes LS, Murthy NS, et al. Identification of Intraarticular and Periarticular Uric Acid Crystals with Dual-Energy CT[J]. Initial Evaluation Radiology. 2011, 261(2):516-524.

[3] Roddy E, Doherty M. Epidemiology of gout[J]. Arthritis Res Ther, 2010,12(6):223.

[4] Zhu Y, Pandya BJ, Choi HK. Comorbidities of gout and hyperuricemia in the US general population: NHANES 2007-2008[J]. The American Journal of Medicine, 125(7), 2012:679-687.

[5] Choi HK, Curhan G. Independent impact of gout on mortality and risk for coronary heart disease. Circulation, 2007,116(8):894-900.

[6] Rees F, Jenkins W, Doherty M. Patients with gout adhere to curative treatment if informed appropriately:proof-of-concept observational study[J]. Ann Rheum Dis, 2013,72(6):826-830.

[7] Pullen C, Walker SN, Fiandt K. Determinants of health-promoting lifestyle behaviors in rural older women[J]. Fam Community Health, 2001,24(2):49-72.

Acknowledgements:

Disclosure of Interest: None declared

DOI: 10.1136/annrheumdis-2017-eular.3370

\section{AB0878 EFFECT OF DIALYSIS AND LOW DOSE URATE-LOWERING ON SERUM URATE LEVELS IN PATIENTS WITH GOUT}

I. Urionagüena ${ }^{1,2}$, S.P. Chinchilla ${ }^{2,3}$, G. Garcia Erauzkin ${ }^{4}$, M.L. Muñiz-Gomez ${ }^{4}$, F. Pérez-Ruiz ${ }^{1,2,3}$. ${ }^{1}$ Rheumatology Division, Cruces University Hospital; ${ }^{2}$ BioCruces Health Research Institute, Barakaldo, Biscay; ${ }^{3}$ University of the Basque Country, Basque Country; ${ }^{4}$ Nephrology Division, Cruces University Hospital, Barakaldo, Biscay, Spain

Background: The effect of dialysis on urate levels (sUA) in patients with gout has not been well characterized. No prospective series are available from the literature, and no recommendation has yet been made by either EULAR or ACR on the topic.

Methods: Exploratory, observational, prospective study. Patients with crystalproven gout and at least one flare the previous year to entrance into dialysis program, either hemodialysis (HD) or home peritoneal dialysis (PD), were followed-up. No urate-lowering drug was prescribed for the first 3-month period, but low-dose allopurinol ( $50 \mathrm{mg} /$ day) was to be prescribed from 6-month visit onwards if tophi (any subcutaneous or ultrasonographic $>10 \mathrm{~mm}$ longest diameter) were present or febuxostat in case allopurinol was not clinically suitable. sUA levels previous to the first dialysis procedure were recorded, along with

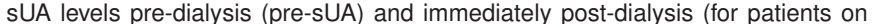
hemodialysis) sUA (post-sUA) were obtained during follow-up at 3,6 , and 12 months of follow-up. No prophylaxis was prescribed, and only adrenocorticotropic hormone $(\mathrm{ACTH})$ analogue or corticosteroids were to be used for the treatment of flares.

Results: 17 patients studied to date: 12 men, mean age 69 (IQ range 62-78). Time from onset of gout was 7years (IQR 1-10) pre-dialysis, and 2 patients entered into dialysis due to prolonged use of NSAIDs because recurrent, longstanding gout over 20 years. Allopurinol $(n=6)$ and febuxostat $(n=2)$ had been prescribed previously to dialysis procedures. ULT was prescribed to 10 patients: 4/4 patients on PD and 6/13 on HD as per in methods; patients treated were prescribed allopurinol $50 \mathrm{mg} /$ day but one who showed HLA-B58 antigen and was treated with febuxostat $80 \mathrm{mg}$ every 3 days. After 12 months 5 patients were lost for follow-up: 2 underwent a renal transplant, 3 were dialyzed at private centers. Follow-up ranged from 12 to 30 months.

There was a significant reduction in sUA at 3-month $(\Delta-2.6 \mathrm{mg} / \mathrm{dl})$, compared to baseline sUA. Reduction of sUA from 3-6-month and 3-12 month was greater in patients treated with ULT (Table).

The rate of flares at 3-month was similar in patients on HD (5/13) than in patients on PD (2/4), only one flare was reported at 6 month follow-up visits, none afterwards. No serious side effect was observed.

Table 1. Change in pre-sUA and post-sUA (mg/dl) globally and with interventions

\begin{tabular}{lccccccc}
\hline Patients/sUA & $\begin{array}{c}0 \\
\text { month }\end{array}$ & $\begin{array}{c}\text { 3rd } \\
\text { month }\end{array}$ & $\begin{array}{c}\text { PostHD- } \\
\text { 3rd month }\end{array}$ & $\begin{array}{c}\text { 6th } \\
\text { month }\end{array}$ & $\begin{array}{c}\text { PostHD- } \\
\text { 6th month }\end{array}$ & $\begin{array}{c}\text { 12th } \\
\text { 12th month }\end{array}$ \\
\hline All $(\mathrm{N}=17)$ & 9.8 & 7.2 & 2.8 & 5.8 & 3.1 & 5.5 & 1.2 \\
Not treated $(\mathrm{N}=10)$ & 9.4 & 6.2 & 3.1 & 5.7 & 3.2 & 5.8 & 1.2 \\
Treated from 6-month $(\mathrm{N}=7)$ & 10.0 & 7.7 & 2.7 & 5.8 & 3.0 & 5.3 & 1.2 \\
PD & 10.2 & 8.0 & & 6.0 & & 5.0 & \\
HD & 9.7 & 6.9 & 2.8 & 5.7 & 3.0 & 5.7 & 1.2 \\
\hline
\end{tabular}

Conclusions: In this exploratory study, dialysis is effective in reducing sUA levels. In hemodialysis, both sUa and postHD-sUA may be needed to better estimate the effect of interventions on SUA. Low dose ULT seems to be effective and may be considered to properly control sUA, but only to be considered in patients with severe (tophaceous) gout.

Disclosure of Interest: I. Urionagüena: None declared, S. P. Chinchilla: None declared, G. Garcia Erauzkin: None declared, M. L. Muñiz-Gomez: None declared, F. Pérez-Ruiz Consultant for: Amgen, Ardea, AstraZeneca, Gruenenthal, Menarini, Speakers bureau: AstraZeneca, Gruenenthal, Menarini

DOI: 10.1136/annrheumdis-2017-eular.2980

\section{AB0879 AN INTERNET TRIAL OF CHERRY EXTRACT VS. DIET MODIFICATION: PATIENT CHARACTERISTICS, GOUT SEVERITY AND DIET CHARACTERISTICS}

J. Singh ${ }^{1}$, G. Mcgwin ${ }^{2}$. ${ }^{1}$ Rheumatology; ${ }^{2}$ Biostatistics, University of Alabama at Birmingham, Birimingham, United States

Background: Gout is often treated with life-long pharmacological therapies. Patients are interested in non-pharmacological interventions as adjunct to these therapies. To our knowledge, non-pharmacological have not been studied in detail.

Objectives: To describe the baseline characteristics of patients with gout enrolled in an Internet pilot study comparing the benefits and harms of diet modification to cherry extract intake.

Methods: Patients were enrolled over an 8-month period using the Internet. Diagnosis of gout was confirmed by contacting their health care provider. We describe the baseline characteristics of patients with physician-confirmed gout, who were randomized in the Internet gout study.

Results: We randomized 83 participants in an Internet gout pilot study, randomized to diet modification $(n=43)$ or cherry extract $(n=40) ; 3$ patients withdrew before receiving intervention. The mean age of study participants was 56 years, (SD, 